\title{
A Ser9Gly Polymorphism in the Dopamine D3 Receptor Gene (DRD3) and Event-Related P300 Potentials
}

\author{
Christoph Mulert*,', Georg Juckel', Ina Giegling', Oliver Pogarell', Gregor Leicht', Susanne Karch', \\ Paraskevi Mavrogiorgou', Hans-Jürgen Möller', Ulrich Hegerl' and Dan Rujescu' \\ 'Department of Psychiatry, University of Munich, LMU, Munich, Germany
}

\begin{abstract}
An important reason for the interest in P300 event-related potentials are findings in patients with psychiatric disorders like schizophrenia or alcoholism in which attenuations of the P300 amplitude are common findings. The P300 wave has been suggested to be a promising endophenotype for genetic research since attenuations of the amplitude and latency can be observed not only in patients but also in relatives. In parallel, the search for genes involved in the pathogenesis of psychiatric disorders has revealed for both, schizophrenia and alcoholism an association with a DRD3 Ser9Gly polymorphism in a number of studies. In the present study, we have investigated I24 unrelated healthy subjects of German descent and have found diminished parietal and increased frontal P300 amplitudes in Gly9 homozygotes in comparison to Ser9 carriers. This finding suggests a possible role of the DRD3 receptor gene in the interindividual variation of P300 amplitudes. Further studies should address the direct role of the DRD3 Ser9Gly polymorphism in attenuated P300 amplitudes in psychiatric disorders like schizophrenia or alcoholism.

Neuropsychopharmacology (2006) 3 I, | 335-1344. doi: I 0. I038/sj.npp. I 300984; published online 4 January 2006
\end{abstract}

Keywords: P300; Dopamine D3 receptor; schizophrenia; alcoholism; evoked potential; LORETA

\section{INTRODUCTION}

A number of neuroelectric measurements are highly heritable (van Beijsterveldt and van Baal, 2002). This is especially true for the amplitude of the event-related P300 potential: the heritability was estimated to be between 0.61 (Wright et al, 2001) and 0.79 (Katsanis et al, 1997) in twin studies. In addition, biologically related family members demonstrate significant inter-family correlations for P300 measures (Eischen and Polich, 1994). This fact and the finding of reduced P300-amplitudes in disorders like schizophrenia (Hegerl et al, 1995; Roth et al, 1981; Strik et al, 1994) or alcoholism (Polich et al, 1994) makes the P300 potential as a strong candidate for an endophenotype approach; although schizophrenia is a hereditable disease, the identification of involved genes is probably limited by the biological heterogenity behind the psychiatric diagnosis.

In a number of family studies, an attenuated P300potential at parietal locations could be detected not only in patients with schizophrenia but also in unaffected siblings (Winterer et al, 2003). Recently, a meta-analysis of articles

\footnotetext{
*Correspondence: Dr C Mulert, Department of Psychiatry, Univeristy of Munich, Nußbaumstraße 7, 80336 München, Germany, Tel: + 4989 5I60 3392, Fax: + 498951605542 ,

E-mail: cmulert@psy.med.uni-muenchen.de

Received 7 October 2004; revised 28 September 2005; accepted 13 October 2005

Online publication: 26 October 2005 at http://www.acnp.org/citations/ Npp 102605040479/default.pdf
}

between 1983 and 2003 including 472 relatives of schizophrenic patients and 513 controls demonstrated significant reductions of the P300 amplitude reductions and latency delays in relatives (Bramon et al, 2005). The authors concluded that the P300 amplitude and the P300 latency are promising alternative phenotypes for genetic research into schizophrenia. Intermediate phenotypes or 'endophenotypes' as biological measures provide a means for identifying the 'downstream' traits or facets of clinical phenotypes, as well as the 'upstream' consequences of genes (Gottesman and Gould, 2003). Event-related potentials are easily obtained from large subjects samples, are stable quantitative measures and therefore interesting for genotype-phenotype association studies.

The search for genes associated with both, the diagnosis of schizophrenia and the P300-amplitude so far revealed a relationship to the Catechol-O-methytransferase (COMT) gene (Gallinat et al, 2003; Glatt et al, 2003) which is involved in dopamine catabolism.

A relationship between the DRD3 receptor gene and schizophrenia has been described in a number of studies (Crocq et al, 1992; Jonsson et al, 2003), while others did not find an association (Ioannidis et al, 2001; Sabate et al, 1994). DRD3 mRNA is predominantly expressed in limbic areas of the brain and may mediate the therapeutic actions of antipsychotic drugs (Suzuki et al, 1998). In a recent PET study with the D3-receptor agonist pramipexol a robust decrease was detected in the bilateral orbitofrontal cortex, thalamus, operculum, posterior and anterior cingulate 
cortex and insula. The authors speculate that dopamine's effects on these regions via D3R may mediate some of the known psychiatric complications of dopamine deficiency or excess (Black et al, 2002). In a recent meta-analysis on the DRD3 Ser9Gly polymorphism in schizophrenia based on 11066 subjects derived from 44 samples, there was a significant association between DRD3 Ser9Gly homozygosity and schizophrenia in the European subsample (based on 14 samples) with an odds ratio of 1.14 but not in the Asian subsample (based on 10 samples).

However, it has been suggested that the published positive findings might reflect a true association in a subgroup of patients who were nonresponder to traditional antipsychotic drugs. In addition, a number of studies suggest a relationship to tardive dyskinesia, sex, and the age of onset. Especially the relationship to tardive dyskinesia was shown nicely in a number of studies (Steen et al, 1997; Basile et al, 1999; Segman et al, 1999; Woo et al, 2002). Since there have been also negative findings (Rietschel et al, 2000) it is important to note that in a recent study investigating a large pooled sample of 780 patients drawn from six research centers, a significant association of the DRD3 genotype with tardive dyskinesia was described (Lerer et al, 2002). The authors also performed a meta-analysis including three other published studies and could again demonstrate a significant relationship between tardive dyskinesia and the DRD3 gly allele carrier status.

Interestingly, beside the fact that a reduced P300amplitude is the typical finding in schizophrenia our own earlier work and studies of other groups suggests that pronounced $\mathrm{P} 300$-amplitude reduction is seen in a subgroup of patients with early onset, bad response to neuroleptics and increased risk for tardive dykinesia (Hegerl et al, 1995; Olichney et al, 1998). Exactly these characteristics have been recently again described to be associated with the DRD3 receptor: 'combining the previous studies, we therefore suppose that the gly allele not only contributes to the pathogenesis of schizophrenia and increases the occurrence of extrapyramidal symptoms including tardive dyskinesia but also associates with a less favorable therapeutic outcome in acutely treated psychotic patients' (Reynolds et al, 2005).

In the abovementioned DRD3 meta-analysis, comorbidity with alcohol abuse, which was described in earlier studies (Krebs et al, 1998) was not detected. However, in families with alcohol abuse, similar to the findings in schizophrenia, diminished P300-amplitudes have been described and a genetic background discussed (Almasy et al, 1999; Blackwood, 2000). Animal studies also suggest a relationship between the D3 receptor and motivational effects of ethanol (Boyce and Risinger, 2002), and a major role concerning the addictive properties of alcohol has recently been suggested (Heidbreder et al, 2004).

A relationship of the $\mathrm{P} 300$ potential to the dopaminergic system was already suggested by findings that the amplitude of the P300 of healthy subjects changes after the application of sulpiride, a dopamine antagonist (Takeshita and Ogura, 1994). Moreover, in Parkinson's Disease (PD), a disease with a reduction of dopaminergic neurons, a prolonged P300 latency has been described. The P300 latency in PD can be at least in parts be influenced by the application of dopaminergic drugs (Stanzione et al, 1990, 1991). For an overview about neurochemical substrates of the P300 see (Frodl-Bauch et al, 1999).

Interestingly, concerning psychiatric diseases with P300 attenuations like schizophrenia and alcoholism (Blackwood, 2000) central dopaminergic dysfunction has been discussed to show analogies in both diseases in the dysfunction of the ventral striatum (nucleus accumbens), which is involved not only in the reinforcing effects of drug intake but also in the pathogenesis of positive schizophrenic symptoms (Heinz, 2002). The ventral striatum may be referred to as dopaminergic reward system and high levels of dopamine D3 receptor mRNA have been described in the nucleus accumbens (Gurevich and Joyce, 1999; Landwehrmeyer et al, 1993). Increased D3 receptor levels in the limbic striatum of patients with schizophrenia have been described in post-mortem investigations (Gurevich et al, 1997) with an influence of the drug history being less likely (Joyce, 2001). Similar, increased D3 receptor levels and D3 receptor mRNA have been described in brains of cocaine overdose victims (Mash and Staley, 1999; Meador-Woodruff et al, 1995; Staley and Mash, 1996), while studies investigating D3-receptor levels in the ventral striatum in alcohol consumption are still required. In addition, a common genetic background for schizophrenia and alcoholism has been suggested (Schuckit et al, 2003).

The P300 potential is usually evoked with an oddball paradigm. Stimuli (for example tones), are presented that way that one stimulus is rare and relevant (for example a button must be pressed) and another stimulus is often presented but irrelevant. The P300 potential is then recorded widely across the scalp some $300 \mathrm{~ms}$ after the rare stimulus. P300-analysis has been limited due to the restrictions of source analysis and the fact that multiple electrical generators in the brain are involved, including the temporo-parietal junction (TPJ) the supplementary motorcortex (SMA) and the anterior cingulate cortex (ACC), the bilateral middle frontal gyrus, the inferior frontal gyrus and the insula. In a recent simultaneous fMRI-EEG-study, we could demonstrate a high degree of accordance in the fMRI-based localizations and ERP-based localizations as described by a current source density approach (Mulert et al, 2004a).

In the present study, we were interested in the relationship of the DRD3 Ser9Gly polymorphism and the P300-potential, both in the conventional analysis of the scalp-amplitudes and using the tomographic current source-density approach LORETA (Mulert et al, 2004b; Pascual-Marqui et al, 1994; Pascual-Marqui et al, 1999). We hypothesized that subjects with the Gly/Gly genotype would show reduced parietal P300 amplitudes in comparison to subjects with the Ser/Ser genotype and that the tomographic comparison would show maximal differences between the groups in the temporo-parietal junction.

\section{MATERIALS AND METHODS}

\section{Subjects}

Unrelated healthy volunteers of German descent were randomly selected from the general population of Munich, Germany, and contacted by mail. In order to exclude subjects with neuropsychiatric disorders or subjects who 
had first-degree relatives with neuropsychiatric disorders, we conducted further screenings before the volunteers were enrolled in the study. First, subjects who responded were initially screened by phone. Their detailed medical and psychiatric histories, and those of their first-degree relatives were assessed using systematic forms. Only German volunteers (ie both their parents were German) were included. Second, they were invited to a comprehensive interview including the Structured Clinical Interview for DSM-IV, SCID I/II (First et al, 1997; Wittchen et al, 1997) to evaluate their lifetime Axis I and II disorder. Psychiatric diagnoses among their first-degree relatives were also assessed using the Family History Assessment Module (Rice et al, 1995). Subjects with relevant somatic diseases or a lifetime history of any Axis I or II psychiatric disorders were excluded. Exclusion criteria for the subjects were also head injury in the history or any medication with influence on the central nervous system (eg, like cortisol, tranquilizers) in the last 3 months. Subjects who had first-degree relatives with a lifetime history of a mental disorder were also excluded. In all, 124 healthy volunteers without a history of neurological or psychiatric disorders and without recent drug consumption were studied (mean age $=45.0 \pm 15$ years; range 19-72 years). After complete description of the study to the subjects, written informed consent was obtained. Subjects were 71 women and 53 men. Auditory dysfunction was excluded by auditory testing of hearing threshold with a Philips audiometer.

\section{Paradigm}

An auditory oddball paradigm with $80 \%$ nontarget stimuli $(540$ tones, $500 \mathrm{~Hz}$ ) and 20\% target stimuli (135 tones, $1000 \mathrm{~Hz}$ ) presented binaurally through headphones in a pseudo randomized order was used $(80 \mathrm{~dB}$ SPL, $40 \mathrm{~ms}$ duration with $10 \mathrm{~ms}$ rise and fall time, interstimulus interval $1.5 \mathrm{~s})$. Subjects were seated with their eyes closed in a reclining chair and had to press a button with their dominant hand after target stimuli.

\section{ERP-Recording}

Recording took place in a sound-attenuated and electrically shielded room adjacent to the recording apparatus (Neuroscan Synamps). Subjects were seated with closed eyes in a slightly reclined chair with a head rest. Evoked potentials were recorded with 33 electrodes referred to $\mathrm{Cz}$ (32 channels). The electrodes were positioned according to the International 10/20 system with the additional electrodes FC1, FC2, FC5, FC6, T1, T2, CP5, CP6, A1, A2, PO9, PO10. Fpz served as ground. Electrode impedance was $<10$ kohms. Data were collected with a sampling rate of $250 \mathrm{~Hz}$ and an analogous band pass filter $(0.16-50 \mathrm{~Hz})$.
$200 \mathrm{~ms}$ prestimulus and $800 \mathrm{~ms}$ poststimulus periods were evaluated. For artifact suppression an amplitude criterion has been used $( \pm 70 \mu \mathrm{V})$ involving all EEG channels and EOG at any time point during the averaging period. Only wave-shapes, based on at least 50 averages were accepted. The P300 amplitude and latency was detected semiautomatically using the BrainVision Analyzer software (Munich) as the most positive value in the timeframe 250-500 ms poststimulus with a visual control afterwards at the electrode positions F3 (left frontal) F4 (right frontal) Fz (fronto-central), P3 (left parietal) P4 (right parietal) and Pz (centro-parietal) each linked to common average.

\section{LORETA}

LORETA assumes that the smoothest of all activity distributions is most plausible ('smoothness assumption') and therefore, a particular current density distribution is found. This fundamental assumption of LORETA directly relies on the neurophysiologic observation of coherent firing of neighboring cortical neurons during stimulus processing (Gray et al, 1989; Llinas, 1988; Silva et al, 1991) and therefore can be seen as a physiologically based constraint. The characteristic feature of the resulting solution is its relatively low spatial resolution, which is a direct consequence of the smoothness constraint. Specifically, the solution produces a 'blurred-localized' image of a point source, conserving the location of maximal activity, but with a certain degree of dispersion. The version of LORETA used in the present study used the digitized Talairach atlas (Talairach and Tournoux, 1988) available as digitized MRI from the Brain Imaging Centre, Montreal Neurologic Institute, estimating the current source density (microAmperes $/ \mathrm{mm}^{2}$ ) distribution for either single time points or epochs of brain electric activity on a dense grid of 2394 voxels at $7 \mathrm{~mm}$ spatial resolution (Pascual-Marqui et al, 1999). The solution space (the three-dimensional space where the inverse EEG problem is solved) was restricted to the gray matter and hippocampus in the Talairach atlas (anatomically based constraint). Localization with regard to spherical and realistic head geometry was done using EEG electrode coordinates reported by Towle et al (1993). A voxel was labeled as gray matter if it met the following three conditions: its probability of being gray matter was higher than that of being white matter, its probability of being gray matter was higher than that of being cerebrospinal fluid, and its probability of being gray matter was higher than 33\% (Pascual-Marqui et al, 1999).

LORETA-analysis was performed in the time-frame $300-$ $600 \mathrm{~ms}$ poststimulus after timeframe-wise normalization. LORETA has been widely used in the last years in order to localize electrical generators of scalp EEG data (Anderer

Table I Genotype and Allele Frequencies of the Ser/Gly Polymorphism in the Dopamine D3 Receptor Gene (DRD3)

\begin{tabular}{lllllll}
\hline & & Ser/Ser & Ser/Gly & Gly/Gly & Ser & Gly \\
\hline Healthy volunteers & $(n=124)$ & $53(42.7 \%)$ & $60(48.4 \%)$ & $11(8.9 \%)$ & $166(66.9 \%)$ & $82(33.1 \%)$
\end{tabular}

Hardy-weinberg equilibrium: $\chi^{2}=0.467, \mathrm{df}=2, p=0.792$ 
et al, 2003; Fallgatter et al, 2003; Gallinat et al, 2002; Mulert et al, 2001) and a good correspondence between fMRI-based localizations and LORETA-maxima has recently been described (Mulert et al, 2004a, 2005).

\section{Genotyping}

Genomic DNA was prepared from $10 \mathrm{ml}$ blood using the Quiagen Maxi DNA Extraction Kit (Hilden, Germany). The distribution of the Ser9Gly polymorphism in the dopamine
DRD3 receptor was determined by PCR and RFLP analysis. Amplification was carried out in $50 \mu \mathrm{l}$ reactions using $50 \mathrm{ng}$ of genomic DNA, $1 \mathrm{U}$ of Taq Polymerase (Life Technologies, Karsruhe, Germany) in presence of $60 \mathrm{mM}$ TrisHCl ( $\mathrm{pH} 9)$, $2 \mathrm{mM} \mathrm{MgCl}_{2}, 15 \mathrm{mM}$ ammonium sulfate, $0.1 \mu \mathrm{M}$ of each primer and $0.05 \mathrm{mM}$ of each dNTP. A $462 \mathrm{bp}$ fragment was amplified using the sense $5^{\prime}$-gctctatctccaactctcaca- $3^{\prime}$ and antisense $5^{\prime}$-aagtctactcacctccaggta- $3^{\prime}$ primer pair. Following an initial denaturation step at $94.0^{\circ} \mathrm{C}$ for $5 \mathrm{~min}$, the DNA was amplified in 39 cycles $\left(94^{\circ} \mathrm{C}\right.$ for $30 \mathrm{~s}, 61^{\circ} \mathrm{C}$ for $30 \mathrm{~s}$, and

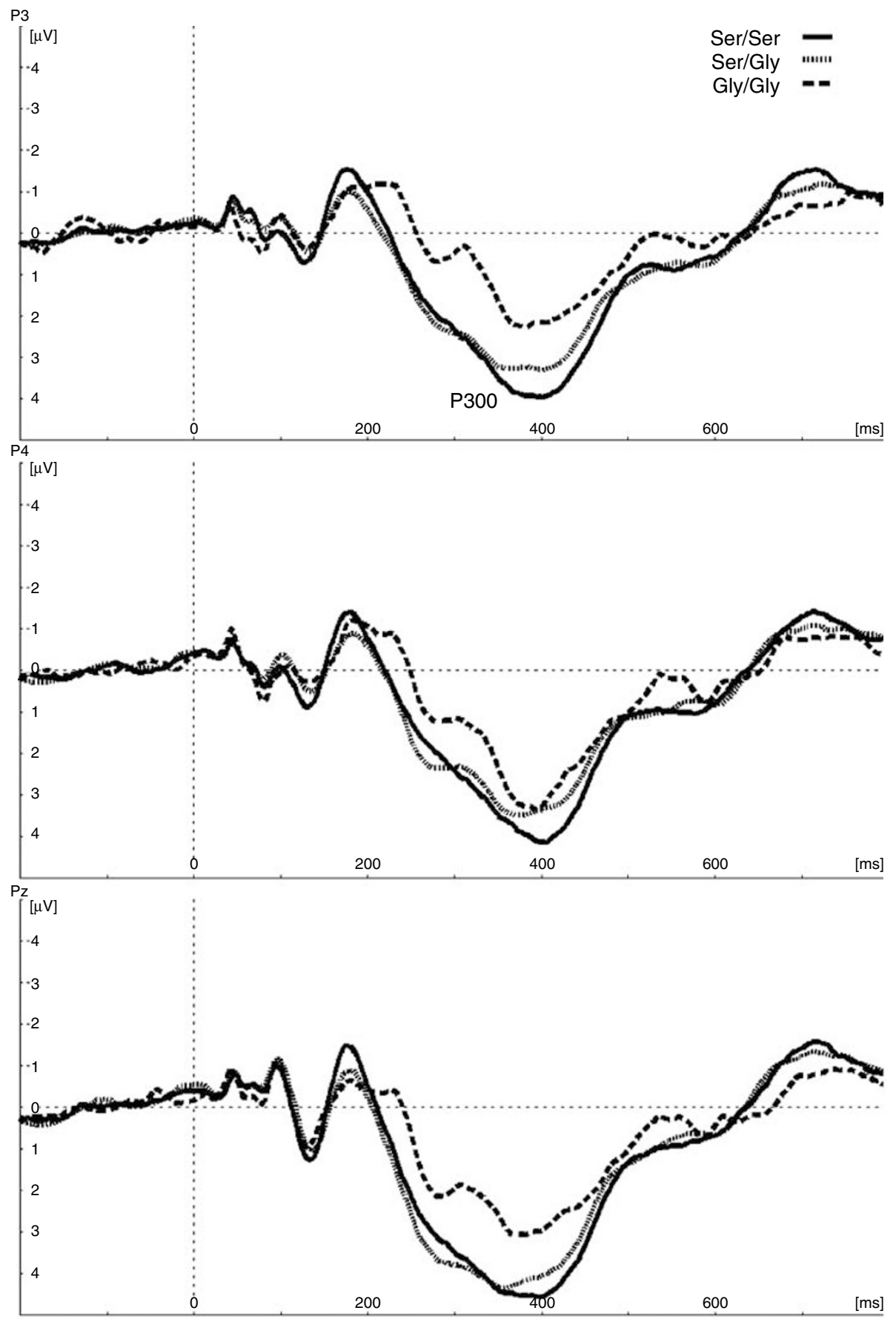

Figure I Grand averages of the P300 potentials at P3, P4 and Pz related to the target tone for the three genotype groups. The attenuated P300 amplitude of the Gly/Gly group is most pronounced on the left side (P3). 
$72^{\circ} \mathrm{C}$ for $30 \mathrm{~s}$ ). The final extention step was $72^{\circ} \mathrm{C}$ for $5 \mathrm{~min}$. The reaction was digested with $12 \mathrm{U}$ MscI (New England Biolabs, Frankfurt, Germany), analyzed by gel electrophoresis in a $2 \%$ agarose gel containing ethidium bromide and visualized under UV light. Cleavage with MscI in the two nonpolymorphic sites gave fragments of size 111 and $47 \mathrm{bp}$. Depending on the absence or presence of the MscI polymorphic restriction site either a fragment of $304 \mathrm{bp}$ (Ser) or two fragments of 206 and $98 \mathrm{bp}$ (Gly) were produced.

\section{Statistical Analyses}

Statistics were performed using the SPSS 12.5. Software (Statistical Package for Social Sciences, SPSS Inc, Chicago). Frequency data were analyzed by $\chi^{2}$ tests. ANOVA or $\chi^{2}$ tests were performed to test for differences concerning sociodemographic variables. For P300 amplitudes, we performed repeated measurement MANCOVAs assessing the main and interaction effects of the within-subjects factors brain region (frontal, parietal) and hemisphere (left,

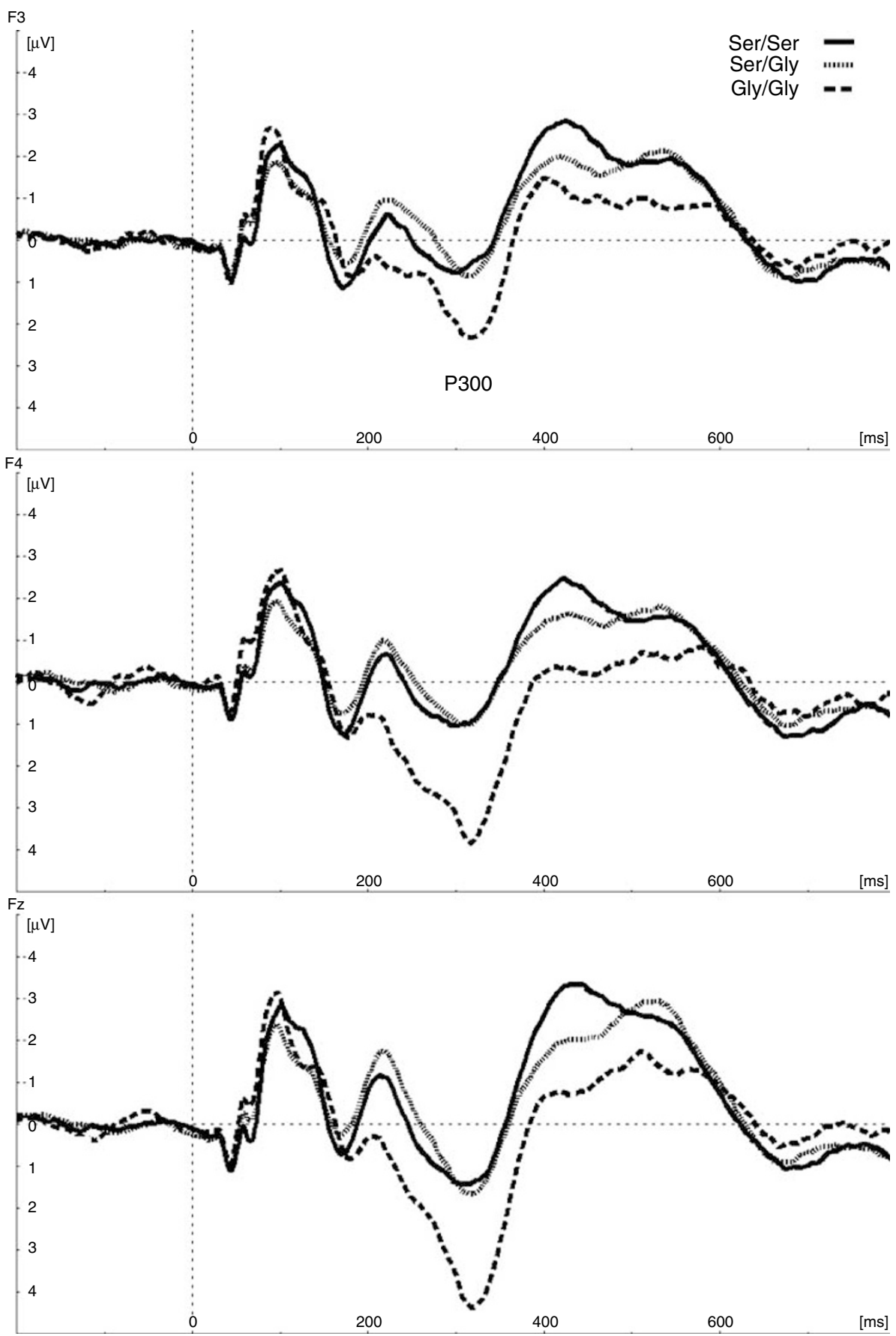

Figure 2 Grand averages of the P300 potentials at F3, F4 and Fz related to the target tone for the genotype groups. The increased P300 amplitude of the Gly/Gly group is most pronounced on the right side (F4). 
right), and the between-subjects genotype (Ser/Ser, Ser/Gly, Gly/Gly, or Allele, respectively). The covariates sex and age were added to the analysis. All analyses used two-tailed estimation of significance. The significance level applied to the data was set at $p<0.05$. The repeated measurements were followed by multivariate analyses for brain regions (frontal, parietal, and central) and genotype (allele respectively) controlled for sex and age.

LORETA comparisons between the Ser/Ser group and the Gly/Gly group was carried out with the implemented statistical nonparametric mapping (SnPM).

\section{RESULTS}

Genotype counts did not significantly deviate from those expected from the Hardy-Weinberg equilibrium $\left(\chi^{2}=0.47\right.$, $\mathrm{df}=2, p=0.79)$. Demographic data are presented in Table 1 for the different genotypes. There was no significant difference between the groups with regard to age $(F=1.36$; $\mathrm{df}=2, p=0.26)$.

Grand averages of auditory P300 referenced to common average are shown for the parietal electrodes $(\mathrm{P} 3, \mathrm{P} 4, \mathrm{Pz})$ in Figure 1 and for the frontal electrodes (F3, F4, Fz) in Figure 2. The mean amplitude of the P300 peak was $5.96 \pm 2.86 \mu \mathrm{V}$ in the Ser/Ser group, $5.68 \pm 2.52 \mu \mathrm{V}$ in the Ser/Gly group, and $4.20 \pm 1.96 \mu \mathrm{V}$ in the Gly/Gly group as measured at $\mathrm{Pz}$. At Fz, the mean amplitude of the P300 peak was $2.61 \pm 2.09 \mu \mathrm{V}$ in the Ser/Ser group, $2.72 \pm 2.00 \mu \mathrm{V}$ in the Ser/Gly group, and $4.95 \pm 2.61 \mu \mathrm{V}$ in the Gly/Gly group.

For P300 amplitudes, we observed an interaction between Region $\times$ Genotype $(\mathrm{F}=4.109, \mathrm{df}=2 / 117 p=0.019)$; as well as Hemisphere $\times$ Genotype $(\mathrm{F}=2.990, \mathrm{df}=2 / 117, p=0.054)$ after controlling for sex and age (Table 2). The genotype had a main effect frontal right $(\mathrm{F}=4.657, \mathrm{df}=2 / 117$, $p=0.011)$ with a reduction in Ser-carriers and parietal left $(\mathrm{F}=3.602, \mathrm{df}=2 / 117, p=0.030)$ with an increased amplitude in Ser-carriers. This effect was similar when looking at alleles or at Ser-carriers vs Gly-homocygotes.

In the statistical nonparametric LORETA comparison between the two homozygous groups (Ser/Ser versus Gly/ Gly) differences were found in frontal and parietal regions as presented in Figure 3 and Table 3.

The mean latency of the P300 peak was $371 \pm 63 \mathrm{~ms}$ in the Ser/Ser group, $351 \pm 65 \mathrm{~ms}$ in the Ser/Gly group and $382 \pm 83 \mathrm{~ms}$ in the Gly/Gly group as measured at Pz. At $\mathrm{Fz}$, the mean latency of the P300 peak was $319 \pm 68 \mathrm{~ms}$ in the Ser/Ser group, $331 \pm 66 \mathrm{~ms}$ in the Ser/Gly group and $311 \pm 15 \mathrm{~ms}$ in the Gly/Gly group. There were no significant differences between the three genotype groups or alleles.

\section{DISCUSSION}

\section{Conventional Analysis}

The main finding of this study were reduced left parietal P300 amplitudes and increased right frontal amplitudes in DRD3 9Gly homozygotes. In a previous study by Tsai et al (2003) investigating the relationship between the DRD3 9Gly polymorphism and the P300 amplitude, the parietal P300 amplitudes have been reported descriptively to be lowest in the Gly9Gly group, however, this effect was not significant, which may be attributed to the relative rare occurrence of Gly9Gly homzygotes $(n=7)$ in this study. Analyses for frontal leads have not been mentioned in this paper. The strongest effects in our data set were present in the left parietal lead P3 and the right frontal lead F4, which

Table 2 Repeated Measurement MANCOVAs and Multivariate Analyses

\begin{tabular}{|c|c|c|c|c|c|c|c|}
\hline & $\mathbf{F}$ & df & $\mathbf{p}$ & & $\mathbf{F}$ & df & $\mathbf{p}$ \\
\hline \multicolumn{8}{|c|}{ (a) Repeated measurement MANCOVAs } \\
\hline G (Genotype) & 1.188 & $2 / 117$ & 0.309 & A (Allele) & 0.273 & $1 / 243$ & 0.602 \\
\hline R (Region) & 36.975 & $1 / 1 \mid 7$ & $<0.001$ & R (Region) & | 10.847 & $1 / 243$ & $<0.001$ \\
\hline $\mathrm{R} \times \mathrm{G}^{\mathrm{a}}$ & 4.109 & $2 / 117$ & 0.019 & RA & 6.460 & $1 / 243$ & 0.012 \\
\hline H (Hemisphere) & 0.635 & $1 / 1 \mid 7$ & 0.427 & $\mathrm{H}$ (Hemisphere) & 0.030 & $1 / 243$ & 0.862 \\
\hline $\mathrm{H} \times \mathrm{G}^{\mathrm{b}}$ & 2.990 & $2 / 117$ & 0.054 & $H \times A$ & $|.35|$ & $1 / 243$ & 0.246 \\
\hline $\mathrm{R} \times \mathrm{H}$ & 0.002 & $1 / 117$ & 0.961 & $\mathrm{R} \times \mathrm{H}$ & 0.038 & $1 / 243$ & 0.846 \\
\hline $\mathrm{R} \times \mathrm{H} \times \mathrm{G}$ & 0.289 & $2 / 117$ & 0.749 & $\mathrm{R} \times \mathrm{H} \times \mathrm{A}$ & 0.153 & $1 / 243$ & 0.696 \\
\hline \multicolumn{8}{|c|}{ (b) Multivariate analyses } \\
\hline Frontal left & 1.053 & $2 / 117$ & 0.352 & Frontal left & $1.69 \mid$ & $1 / 243$ & 0.195 \\
\hline Frontal right ${ }^{c}$ & 4.657 & $2 / 117$ & 0.011 & Frontal right & 4.443 & $1 / 243$ & 0.036 \\
\hline Frontal central & 2.247 & $2 / 117$ & 0.110 & Frontal central & 3.395 & $1 / 243$ & 0.067 \\
\hline Parietal left ${ }^{d}$ & 3.602 & $2 / 117$ & 0.030 & Parietal left & 5.375 & $1 / 243$ & 0.021 \\
\hline Parietal right & 2.347 & $2 / 117$ & 0.100 & Parietal right & 3.645 & $1 / 243$ & 0.057 \\
\hline Parietal central & 2.547 & $2 / 117$ & 0.083 & Parietal central & 2.704 & $1 / 243$ & 0.101 \\
\hline
\end{tabular}

${ }^{a}$ (Ser-Carrier vs Gly Homocygotes) $F=6.563, d f=1 / 119, p=0.012$.

${ }^{b}$ (Ser-Carrier vs Gly Homocygotes) $\mathrm{F}=6.174, \mathrm{df}=1 / 119, p=0.014$.

${ }^{c}$ (Ser-Carrier vs Gly Homocygotes) $F=9.431, d f=1 / 119, p=0.003$.

d(Ser-Carrier vs Gly Homocygotes) $F=4.516, d f=1 / 119, p=0.036$ 

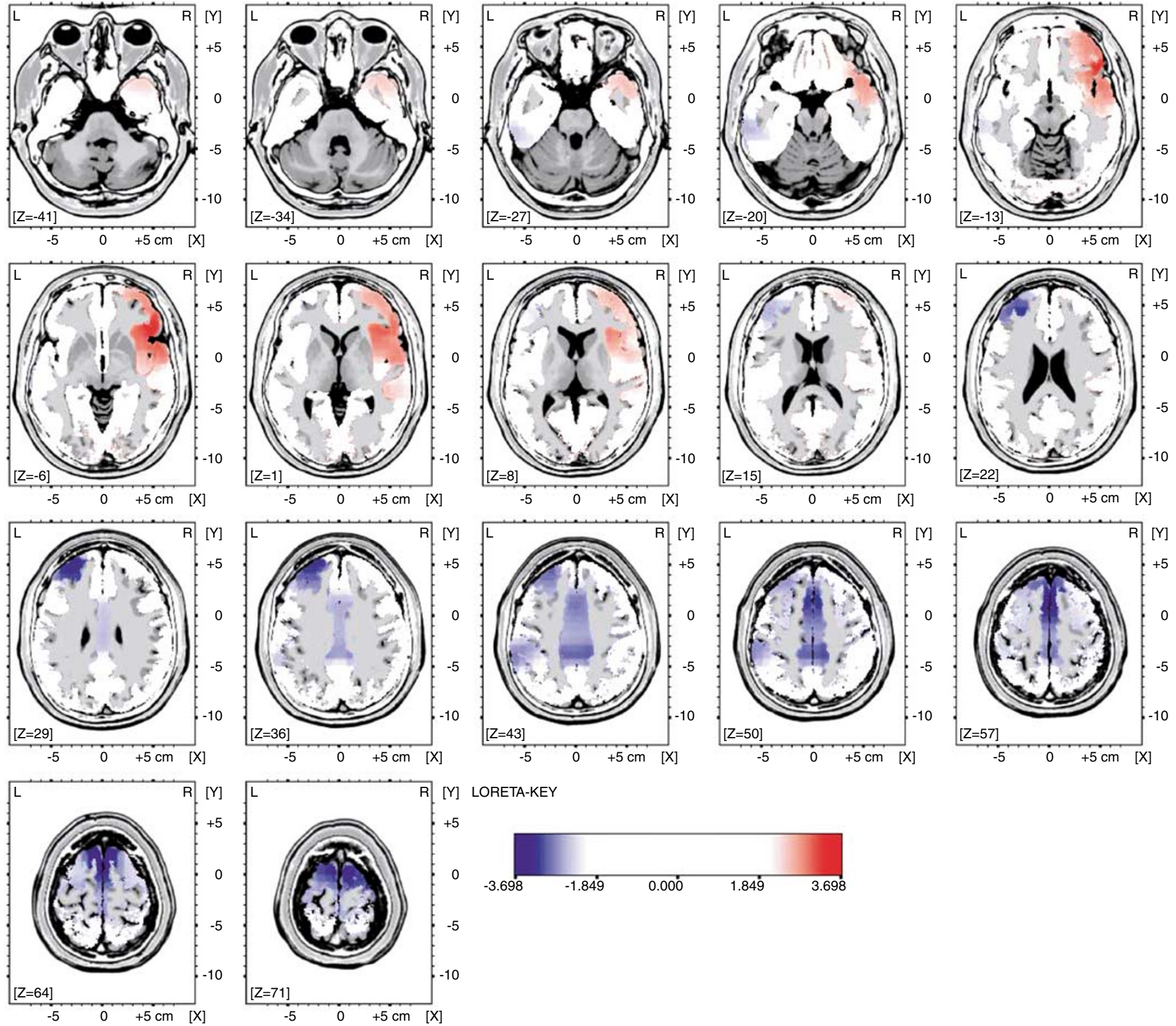

Figure 3 LORETA-nonparametric comparison between the Gly/Gly group and the Ser/Ser group. Red color means increased activity in the Gly/Gly group, blue color increased activity in the Ser/Ser group.

are both not reported in the study by Tsai investigating healthy female Han-Chinese subjects. In this context, it might be of interest that in the recent meta-analysis on the DRD3 Ser9Gly variation in schizophrenia, no association was found in the Asian subsample but only in the European subsample suggesting a possible role of ethnicity in this context. In comparison to other European samples, the observed Ser allele frequency of 66.9 in the present study fits well in the expected range of $65.7-71 \%$ (Jonsson et al, 2004; Joyce et al, 2003).

Comparing our results of $\mathrm{P} 300$-amplitude alterations in the Gly9Gly group with the findings in schizophrenia, a parallel in the finding of reduced parietal amplitudes is obvious: reduced parietal amplitudes are the common finding in a large number of studies investigating patients with schizophrenia (Blackwood, 2000; Bruder et al, 2001; Demiralp et al, 2002). However, in previous studies it has been suggested that this $\mathrm{P} 300$-amplitude attenuation is most pronounced in a subgroup of patients with early onset, increased risk for tardive dyskinesia and insufficient response to neuroleptic medication (Hegerl et al, 1995; Juckel et al, 1996; Olichney et al, 1998). Concerning our finding of increased prefrontal activity in the Gly9Glyhomozygotes and findings in schizophrenia, the situation is more complex: while most authors describe reduced frontal P300 amplitudes (Martin-Loeches et al, 2001), some did not find any difference between patients and controls and some even describe increased frontal amplitudes in schizophrenia. Interestingly, in a recent P300 study in 66 schizophrenic patients and 115 healthy siblings, increased frontal amplitudes have been described both in patients and in unaffected siblings (Winterer et al, 2003). In addition, in a recent 128-channel P300 study, investigating twenty patients with schizophrenia in comparison to controls using individual MRIs for a statistical LORETA-approach with statistical parametric mapping (SPM), reduced left 
Table 3 Statistical Nonparametric Comparisons between the Current Source Density Values of the Gly/Gly and the Ser/Ser Group

\begin{tabular}{lccc}
\hline Region & $\begin{array}{c}\mathbf{X ~ Y ~ Z ~} \\
\text { (Talairach) }\end{array}$ & $\begin{array}{c}\text { Bordmann } \\
\text { area }\end{array}$ & T-value \\
\hline Increased activity in the Ser/Ser group versus the Gly/Gly group & \\
Superior frontal gyrus (left) & $-3,-17,64$ & 6 & $3.70^{*}$ \\
Middle frontal gyrus (left) & $-31,45,29$ & 10 & $3.29^{\dagger}$ \\
Paracentral lobule (right) & II, -39, 50 & 5 & $3.08^{\ddagger}$ \\
Temporo-parietal junction (left) & $-59,-39,43$ & 40 & $2.82^{\ddagger}$ \\
Middle temporal gyrus (left) & $-66,-32,20$ & 21 & $2.53^{\ddagger}$ \\
& & & \\
Increased activity in the Gly/Gly group versus the Ser/Ser group & \\
Inferior frontal gyrus (right) & $46,31,-6$ & 47 & $3.34^{\dagger}$ \\
Middle temporal gyrus (right) & $46,-39,1$ & 22 & $3.05^{\ddagger}$ \\
Middle frontal gyrus (right) & $39 ; 59 ;-13$ & 11 & $2.82^{\ddagger}$ \\
\hline
\end{tabular}

${ }^{*} p$-value $<0.05,{ }^{\dagger} p$-value $<0.10$; ${ }^{\ddagger}$ significant cluster.

Analysis was performed in the time-frame $300-600$ ms poststimulus.

inferior parietal activity was described in combination with increased right orbito-frontal activity in the schizophrenic group (Pae et al, 2003). This pattern seems to be similar to our finding in the Gly9Gly-group in comparison to the Ser9Ser-homozygotes.

Reduced parietal P300 amplitudes are also a common finding in alcoholism (Pfefferbaum et al, 1991). In addition frontal amplitudes are also typically reduced (Cohen et al, 1995; George et al, 2004). The reduced parietal P300 would be in line with our present findings but the right frontal increase in the present study does not fit. However, the number of studies reporting amplitudes of frontal electrodes in alcoholism is relatively small and toxic alcohol effects on frontal lobe function have to be taken into account.

\section{LORETA-Analysis}

In the subsequent tomographic current source density approach with LORETA, comparing both homozygote groups (Ser9Ser and Gly9Gly) we did not only investigate a single time-point (eg fixed on the P300 peak at a selected electrode) but used the large timeframe $(300-600 \mathrm{~ms}$ poststimulus) with a more comprehensive overview about involved brain regions at the expense of lower statistical significance for the any respective finding. Concerning the increased right frontal activity in the Gly9Gly group in comparison to the Ser9Ser group on the scalp electrode level, correspondingly the highest $t$-value in the LORETAanalysis was found in the right inferior frontal gyrus, Brodmann area 47. Lowering the significance level, an additional cluster in the right middle temporal gyrus turned out to be stronger activated in the Gly9Gly group. On this level, several regions were also less activated in the Gly9Gly group, including the left inferior temporo-parietal junction (Brodmann 40), the paracentral lobule and the left superior frontal gyrus. In addition, significantly increased activity in the superior frontal gyrus was detected in the Ser9Ser group in comparison to the Gly9Gly group.
This complex tomographic activation pattern is for the most part in line with the scalp EEG data and is offering a more precise localization of the right frontal and left parietal P300-amplitude findings. In addition it also expands the limited view of a peak picking approach in taking into account an increased time-frame and an increased number of electrodes.

\section{Limitations}

Since the Gly allele is relatively rare, the total number of 11 subjects in the critical Gly/Gly group with only three males seems to be critically low. In addition, there are probably multiple causes for reduced P300 amplitudes in both schizophrenia and alcoholism. The definite role of the DRD3 Ser9Gly polymorphism for P300 amplitude reductions in schizophrenia and alcoholism cannot be finally determined by this investigation of healthy volunteers. Concerning the LORETA-analyses, besides the more detailed description of reduced parietal and increased right frontal activity in the Gly/Gly group additional results (eg in temporal regions) have been found. This might well be due to the fact, that in the tomographic all channel information is included. However, since these findings are significant only at liberal $p$-values, further confirmation and replication is necessary.

Summarizing our results, we could find a relationship between the DRD3 9Gly and the P300 amplitude. The alterations in the Gly9Gly homozygotes (reduced parietal and increased frontal activity) have some similarity with typical findings in schizophrenia and alcoholism. This suggests that the P300 findings might be in fact regarded as an intermediate or endophenotype. Very large-scale family studies are necessary to investigate the possibility that reduced parietal and increased frontal amplitudes are present in DRD3 9Gly homozygotes.

\section{REFERENCES}

Almasy L, Porjesz B, Blangero J, Chorlian DB, O'Connor SJ, Kuperman $S$ et al (1999). Heritability of event-related brain potentials in families with a history of alcoholism. Am J Med Genet 88: 383-390.

Anderer P, Saletu B, Semlitsch HV, Pascual-Marqui RD (2003). Non-invasive localization of P300 sources in normal aging and age-associated memory impairment. Neurobiol Aging 24: 463-479.

Basile VS, Masellis M, Badri F, Paterson AD, Meltzer HY, Lieberman JA et al (1999). Association of the MscI polymorphism of the dopamine D3 receptor gene with tardive dyskinesia in schizophrenia. Neuropsychopharmacology 21: 17-27.

Black KJ, Hershey T, Koller JM, Videen TO, Mintun MA, Price JL et al (2002). A possible substrate for dopamine-related changes in mood and behavior: prefrontal and limbic effects of a D3preferring dopamine agonist. Proc Natl Acad Sci USA 99: 1711317118.

Blackwood D (2000). P300, a state and a trait marker in schizophrenia (In Process Citation). Lancet 355: 771-772.

Boyce JM, Risinger FO (2002). Dopamine D3 receptor antagonist effects on the motivational effects of ethanol. Alcohol 28: 47-55.

Bramon E, McDonald C, Croft RJ, Landau S, Filbey F, Gruzelier $\mathrm{JH}$ et al (2005). Is the $\mathrm{P} 300$ wave an endophenotype for 
schizophrenia? A meta-analysis and a family study. Neuroimage 27: 960-968.

Bruder GE, Kayser J, Tenke CE, Friedman M, Malaspina D, Gorman JM et al (2001). Event-related potentials in schizophrenia during tonal and phonetic oddball tasks: relations to diagnostic subtype, symptom features and verbal memory. Biol Psychiatry 50: 447-452.

Cohen HL, Wang W, Porjesz B, Begleiter H (1995). Auditory P300 in young alcoholics: regional response characteristics. Alcohol Clin Exp Res 19: 469-475.

Crocq MA, Mant R, Asherson P, Williams J, Hode Y, Mayerova A et al (1992). Association between schizophrenia and homozygosity at the dopamine D3 receptor gene. J Med Genet 29: 858-860.

Demiralp T, Ucok A, Devrim M, Isoglu-Alkac U, Tecer A, Polich J (2002). N2 and P3 components of event-related potential in firstepisode schizophrenic patients: scalp topography, medication, and latency effects. Psychiatry Res 111: 167-179.

Eischen SE, Polich J (1994). P300 from families. Electroencephalogr Clin Neurophysiol 92: 369-372.

Fallgatter AJ, Bartsch AJ, Zielasek J, Herrmann MJ (2003). Brain electrical dysfunction of the anterior cingulate in schizophrenic patients. Psychiatry Res 124: 37-48.

First MB, Spitzer RL, Gibbon M, Williams JB (1997). Structured Clinical Interview for DSM-IV Axis I and II Disorders. American Psychiatric Press: Washington, DC.

Frodl-Bauch T, Bottlender R, Hegerl U (1999). Neurochemical substrates and neuroanatomical generators of the event-related P300. Neuropsychobiology 40: 86-94.

Gallinat J, Bajbouj M, Bajobouji M, Rentzsch J, Senkowski D, Schunter J et al (2003). Association of the G1947A COMT (Val(108/158)Met) gene polymorphism with prefrontal P300 during information processing. Biol Psychiatry 54: 40-48.

Gallinat J, Mulert C, Sander T, Schlattmann P, Xu K, Ferro EF et al (2002). Frontal and temporal dysfunction of auditory stimulus processing in schizophrenia. Neuroimage 17: 110-127.

George MR, Potts G, Kothman D, Martin L, Mukundan CR (2004). Frontal deficits in alcoholism: an ERP study. Brain Cogn 54: 245-247.

Glatt SJ, Faraone SV, Tsuang MT (2003). Association between a functional catechol $O$-methyltransferase gene polymorphism and schizophrenia: meta-analysis of case-control and family-based studies. Am J Psychiatry 160: 469-476.

Gottesman II, Gould TD (2003). The endophenotype concept in psychiatry: etymology and strategic intentions. Am J Psychiatry 160: 636-645.

Gray CM, Konig P, Engel AK, Singer W (1989). Oscillatory responses in cat visual cortex exhibit inter-columnar synchronization which reflects global stimulus properties. Nature 338: 334-337.

Gurevich EV, Bordelon Y, Shapiro M, Arnold SE, Gur RE, Joyce JN (1997). Mesolimbic dopamine D3 receptors and use of antipsychotics in patients with schizophrenia. A postmortem study. Arch Gen Psychiatry 54: 225-232.

Gurevich EV, Joyce JN (1999). Distribution of dopamine D3 receptor expressing neurons in the human forebrain: comparison with D2 receptor expressing neurons. Neuropsychopharmacology 20: $60-80$.

Hegerl U, Juckel G, Muller-Schubert A, Pietzcker A, Gaebel W (1995). Schizophrenics with small P300: a subgroup with a neurodevelopmental disturbance and a high risk for tardive dyskinesia? Acta Psychiatr Scand 91: 120-125.

Heidbreder CA, Andreoli M, Marcon C, Thanos PK, Ashby Jr CR, Gardner EL (2004). Role of dopamine D3 receptors in the addictive properties of ethanol. Drugs Today (Barc) 40: 355-365.

Heinz A (2002). Dopaminergic dysfunction in alcoholism and schizophrenia - psychopathological and behavioral correlates. Eur Psychiatry 17: 9-16.
Ioannidis JP, Ntzani EE, Trikalinos TA, Contopoulos-Ioannidis DG (2001). Replication validity of genetic association studies. Nat Genet 29: 306-309.

Jonsson EG, Flyckt L, Burgert E, Crocq MA, Forslund K, MattilaEvenden $M$ et al (2003). Dopamine D3 receptor gene Ser9Gly variant and schizophrenia: association study and meta-analysis. Psychiatr Genet 13: 1-12.

Jonsson EG, Kaiser R, Brockmoller J, Nimgaonkar VL, Crocq MA (2004). Meta-analysis of the dopamine D3 receptor gene (DRD3) Ser9Gly variant and schizophrenia. Psychiatr Genet 14: 9-12.

Joyce JN (2001). D2 but not D3 receptors are elevated after 9 or 11 months chronic haloperidol treatment: influence of withdrawal period. Synapse 40: 137-144.

Joyce PR, Rogers GR, Miller AL, Mulder RT, Luty SE, Kennedy MA (2003). Polymorphisms of DRD4 and DRD3 and risk of avoidant and obsessive personality traits and disorders. Psychiatry Res 119: $1-10$.

Juckel G, Muller-Schubert A, Gaebel W, Hegerl U (1996). Residual symptoms and P300 in schizophrenic outpatients. Psychiatry Res 65: 23-32.

Katsanis J, Iacono WG, McGue MK, Carlson SR (1997). P300 eventrelated potential heritability in monozygotic and dizygotic twins. Psychophysiology 34: 47-58.

Krebs MO, Sautel F, Bourdel MC, Sokoloff P, Schwartz JC, Olie JP et al (1998). Dopamine D3 receptor gene variants and substance abuse in schizophrenia. Mol Psychiatry 3: 337-341.

Landwehrmeyer B, Mengod G, Palacios JM (1993). Dopamine D3 receptor mRNA and binding sites in human brain. Brain Res Mol Brain Res 18: 187-192.

Lerer B, Segman RH, Fangerau H, Daly AK, Basile VS, Cavallaro R et al (2002). Pharmacogenetics of tardive dyskinesia: combined analysis of 780 patients supports association with dopamine D3 receptor gene Ser9Gly polymorphism. Neuropsychopharmacology 27: 105-119.

Llinas RR (1988). The intrinsic electrophysiological properties of mammalian neurons: insights into central nervous system function. Science 242: 1654-1664.

Martin-Loeches M, Molina V, Munoz F, Hinojosa JA, Reig S, Desco $\mathrm{M}$ et al (2001). P300 amplitude as a possible correlate of frontal degeneration in schizophrenia. Schizophr Res 49: 121-128.

Mash DC, Staley JK (1999). D3 dopamine and kappa opioid receptor alterations in human brain of cocaine-overdose victims. Ann NY Acad Sci 877: 507-522.

Meador-Woodruff JH, Little KY, Damask SP, Watson SJ (1995). Effects of cocaine on D3 and D4 receptor expression in the human striatum. Biol Psychiatry 38: 263-266.

Mulert C, Gallinat J, Pascual-Marqui H, Dorn H, Frick K, Schlattmann $\mathrm{P}$ et al (2001). Reduced event-related current density in the anterior cingulate cortex in schizophrenia. Neuroimage 13: 589-600.

Mulert C, Jager L, Schmitt R, Bussfeld P, Pogarell O, Moller HJ et al (2004a). Integration of fMRI and simultaneous EEG: towards a comprehensive understanding of localization and time-course of brain activity in target detection. Neuroimage 22: 83-94.

Mulert C, Jager L, Juckel G, Rujescu D, Giegling I, Rupp D et al (2005). Sound level dependence of the primary auditory cortex: Simultaneous measurement with 61-channel EEG and fMRI. Neuroimage 28: 49-58.

Mulert C, Pogarell O, Propp S, Karch S, Stormann S, Pogarell O et al (2004b). The neural basis of the P300 potential. Focus on the time-course of the underlying cortical generators. Eur Arch Psychiatry Clin Neurosci 254: 190-198.

Olichney JM, Iragui VJ, Kutas M, Nowacki R, Morris S, Jeste DV et al (1998). Relationship between auditory P300 amplitude and age of onset of schizophrenia in older patients. Psychiatry Res 79: 241-254. 
Pae JS, Kwon JS, Youn T, Park HJ, Kim MS, Lee B et al (2003). LORETA imaging of P300 in schizophrenia with individual MRI and 128-channel EEG. Neuroimage 20: 1552-1560.

Pascual-Marqui RD, Lehmann D, Lehmann D (1999). Low resolution brain electromagnetic tomography (LORETA) functional imaging in acute, neuroleptic-naive, first-episode, productive schizophrenia. Psychiatry Res 90: 169-179.

Pascual-Marqui RD, Michel CM, Koenig T, Kochi K, Merlo MC, Hell D et al (1994). Low resolution electromagnetic tomography: a new method for localizing electrical activity in the brain. Int $J$ Psychophysiol 18: 49-65.

Pfefferbaum A, Ford JM, White PM, Mathalon D (1991). Eventrelated potentials in alcoholic men: P3 amplitude reflects family history but not alcohol consumption. Alcohol Clin Exp Res 15: 839-850.

Polich J, Pollock VE, Bloom FE (1994). Meta-analysis of P300 amplitude from males at risk for alcoholism. Psychol Bull 115: 55-73.

Reynolds GP, Yao Z, Zhang X, Sun J, Zhang Z (2005). Pharmacogenetics of treatment in first-episode schizophrenia: D3 and 5-HT2C receptor polymorphisms separately associate with positive and negative symptom response. Eur Neuropsychopharmacol 15: 143-151.

Rice JP, Reich T, Bucholz KK, Neuman RJ, Fishman R, Rochberg N (1995). Comparison of direct interview and family history diagnoses of alcohol dependence. Alcohol Clin Exp Res 19: 1018-1023.

Rietschel M, Krauss H, Muller DJ, Schulze TG, Knapp M, Marwinski $\mathrm{K}$ et al (2000). Dopamine D3 receptor variant and tardive dyskinesia. Eur Arch Psychiatry Clin Neurosci 250: 31-35.

Roth WT, Pfefferbaum A, Kelly AF, Berger PA, Kopell BS (1981). Auditory event-related potentials in schizophrenia and depression. Psychiatry Res 4: 199-212.

Sabate O, Campion D, d'Amato T, Martres MP, Sokoloff P, Giros B et al (1994). Failure to find evidence for linkage or association between the dopamine D3 receptor gene and schizophrenia. Am J Psychiatry 151: 107-111.

Schuckit MA, Kelsoe JR, Braff DL, Wilhelmsen KC (2003). Some possible genetic parallels across alcoholism, bipolar disorder and schizophrenia. J Stud Alcohol 64: 157-159.

Segman R, Neeman T, Heresco-Levy U, Finkel B, Karagichev L, Schlafman $M$ et al (1999). Genotypic association between the dopamine D3 receptor and tardive dyskinesia in chronic schizophrenia. Mol Psychiatry 4: 247-253.

Silva LR, Amitai Y, Connors BW (1991). Intrinsic oscillations of neocortex generated by layer 5 pyramidal neurons. Science 251: $432-435$.

Staley JK, Mash DC (1996). Adaptive increase in D3 dopamine receptors in the brain reward circuits of human cocaine fatalities. J Neurosci 16: 6100-6106.
Stanzione P, Fattapposta F, Tagliati M, D’Alessio C, Marciani MG, Foti A et al (1990). Dopaminergic pharmacological manipulations in normal humans confirm the specificity of the visual (PERG-VEP) and cognitive (P300) electrophysiological alterations in Parkinson's disease. Electroencephalogr Clin Neurophysiol Suppl 41: 216-220.

Stanzione P, Fattapposta F, Giunti P, D'Alessio C, Tagliati M, Affricano C et al (1991). P300 variations in parkinsonian patients before and during dopaminergic monotherapy: a suggested dopamine component in P300. Electroencephalogr Clin Neurophysiol 80: 446-453.

Steen VM, Lovlie R, MacEwan T, McCreadie RG (1997). Dopamine D3-receptor gene variant and susceptibility to tardive dyskinesia in schizophrenic patients. Mol Psychiatry 2: 139-145.

Strik WK, Dierks T, Franzek E, Stober G, Maurer K (1994). P300 in schizophrenia: interactions between amplitudes and topography. Biol Psychiatry 35: 850-856.

Suzuki M, Hurd YL, Sokoloff P, Schwartz JC, Sedvall G (1998). D3 dopamine receptor mRNA is widely expressed in the human brain. Brain Res 779: 58-74.

Takeshita S, Ogura C (1994). Effect of the dopamine D2 antagonist sulpiride on event-related potentials and its relation to the law of initial value. Int J Psychophysiol 16: 99-106.

Talairach J, Tournoux P (1988). Co-Planar Stereotaxic Atlas of the Human Brain. Stuttgart: Thieme.

Towle VL, Bolanos J, Suarez D, Tan K, Grzeszczuk R, Levin DN et al (1993). The spatial location of EEG electrodes: locating the best-fitting sphere relative to cortical anatomy. Electroencephalogr Clin Neurophysiol 86: 1-6.

Tsai SJ, Yu YW, Chen TJ, Chen CM, Hong CJ (2003). Association analysis for dopamine D3 receptor, dopamine D4 receptor and dopamine transporter genetic polymorphisms and P300 event-related potentials for normal young females. Psychiatr Genet 13: 51-53.

van Beijsterveldt CE, van Baal GC (2002). Twin and family studies of the human electroencephalogram: a review and a metaanalysis. Biol Psychol 61: 111-138.

Winterer G, Egan MF, Raedler T, Sanchez C, Jones DW, Coppola R et al (2003). P300 and genetic risk for schizophrenia. Arch Gen Psychiatry 60: 1158-1167.

Wittchen HU, Zaudig M, Fydrich T (1997). Strukturiertes Klinisches Interview für DSM-IV, Achse I und II: Persönlichkeitsstörungen (Structured clinical interviews for DSM-IV Axis I and II disorders). Hogrefe: Goettingen, Germany.

Woo SI, Kim JW, Rha E, Han SH, Hahn KH, Park CS et al (2002). Association of the Ser9Gly polymorphism in the dopamine D3 receptor gene with tardive dyskinesia in Korean schizophrenics. Psychiatr Clin Neurosci 56: 469-474.

Wright MJ, Hansell NK, Geffen GM, Geffen LB, Smith GA, Martin NG (2001). Genetic influence on the variance in P3 amplitude and latency. Behav Genet 31: 555-565. 